Provided for non-commercial research and education use. Not for reproduction, distribution or commercial use.

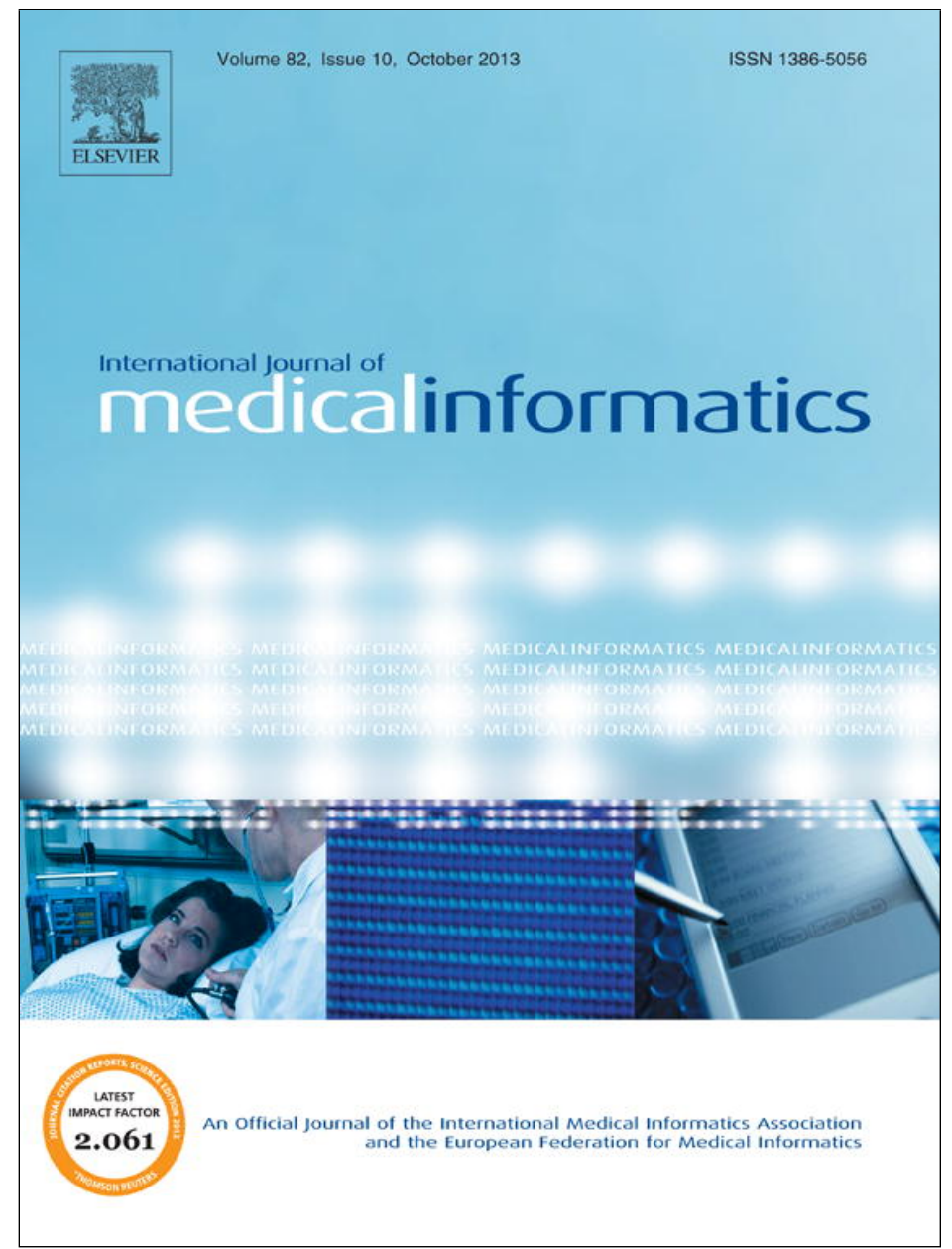

This article appeared in a journal published by Elsevier. The attached copy is furnished to the author for internal non-commercial research and education use, including for instruction at the authors institution and sharing with colleagues.

Other uses, including reproduction and distribution, or selling or licensing copies, or posting to personal, institutional or third party websites are prohibited.

In most cases authors are permitted to post their version of the article (e.g. in Word or Tex form) to their personal website or institutional repository. Authors requiring further information regarding Elsevier's archiving and manuscript policies are encouraged to visit:

http://www.elsevier.com/authorsrights 


\title{
Evaluation of a comprehensive EHR based on the DeLone and McLean model for IS success: Approach, results, and success factors
}

\author{
Claus Bossen ${ }^{a, *}$, Lotte Groth Jensen ${ }^{a, b}$, Flemming Witt Udsen ${ }^{b, c}$ \\ ${ }^{a}$ Information Studies, Department of Aesthetics and Communication, Aarhus University, Denmark \\ $\mathrm{b}$ Department of Health Technology Assessment, Institute of Public Health, Aarhus University, Denmark \\ ${ }^{c}$ Danish Center for Health Care Improvements, Faculty of Social Sciences \& Faculty of Medicine, Aalborg University, Denmark
}

\section{A R T I C L E I N F O}

\section{Article history:}

Received 11 July 2012

Received in revised form

29 May 2013

Accepted 30 May 2013

\section{Keywords:}

Case study

Comprehensive electronic health record

DeLone and McLean success model

Evaluation

Electronic health record

Hospitals

Mixed-methods

Shake down phase

\section{A B S T R A C T}

Objective: The article describes the methodological approach to, and results of an evaluation of a comprehensive electronic health record (EHR) in the shake down phase, shortly after its implementation at a regional hospital in Denmark.

Design: A formative evaluation based on a mixed-methods case study, designed to be interactive and concurrent was conducted at two hospital departments based on the updated DeLone and McLean framework for evaluating information systems success.

Methods: To ascertain user assessments of the EHR, we distributed a questionnaire two months after implementation to four groups of staff (physicians, nurses, medical secretaries, and physiotherapists; $n=244$ ), and at the same time we conducted thirteen individual, semistructured interviews with representatives from these four groups. Subsequently, seven follow-up focus group interviews were conducted with the four above-mentioned groups, in order to go deeper into specific user assessments. Simultaneously, focus group interviews with two IT departments and the implementation team were conducted, to gain insight into system provider assessments of the implementation process and the EHR. Before, during, and after implementation, $88 \mathrm{~h}$ of ethnographic observation were carried out, to give the researchers an understanding of the daily routine of staff, and their use of health records. Finally, daily system performance data were obtained, to gather factual information on system response and downtime.

Results: Overall, staff had positive experiences with the EHR and its operational reliability, response time, login and support. Performance was acceptable. Medical secretaries found the use of the patient administration module cumbersome, and physicians found the establishment of the overview of professionally relevant data challenging. There were demands for improvements to these and other functionalities, and for the EHR to be integrated with other systems and databases.

Limitations: Evaluations immediately following implementation are inherently difficult, but was required because a key role was to inform decision-making upon enrollment at other hospitals and systematically identify barriers in this respect. The strength of the evaluation is the mixed-methods approach. Further, the evaluation was based on assessments from staff in two departments that comprise around $50 \%$ of hospital staff. A weakness may be that staff assessment plays a major role in interviews and survey. These though are supplemented by performance data and observation. Also, the evaluation primarily reports upon

\footnotetext{
* Corresponding author. Tel.: +4589429243.

E-mail address: imvcb@hum.au.dk (C. Bossen). 1386-5056/\$ - see front matter @ 2013 Elsevier Ireland Ltd. All rights reserved. http://dx.doi.org/10.1016/j.ijmedinf.2013.05.010
} 
the dimension 'user satisfaction', since use of the EHR is mandatory. Finally, generalizability may be low, since the evaluation was not based on a validated survey. All in all, however, the evaluation proposes an evaluation design in constrained circumstances.

Conclusions: Despite inherent limitations, evaluation of a comprehensive EHR shortly after implementation may be necessary, can be conducted, and may inform political decision making. The updated DeLone and McLean framework was constructive in the overall design of the evaluation of the EHR implementation, and allowed the model to be adapted to the health care domain by being methodological flexible. The mixed-methods case study produced valid and reliable results, and was accepted by staff, system providers, and political decision makers. The successful implementation may be attributed to the configurability of the EHR and to factors such as an experienced, competent implementation organization at the hospital, upgraded soft- and hardware, and a high degree of user involvement.

(c) 2013 Elsevier Ireland Ltd. All rights reserved.

\section{1. \\ Introduction}

Substantial capital and high expectations are presently invested in the implementation of health information systems and electronic health records (EHRs) in the USA [1], and in European countries such as the UK [2], Austria [3], and Norway [4] (for a comprehensive overview of studies of EHRs, see [5]). In Denmark, efforts to develop and implement EHRs have been part of national IT strategies since the mid1990s, with relatively high ambitions of cross-professional, structured records that enhance clinical work, planning, and research [6,7]. Presently, all Danish hospitals have electronic patient administration systems (PAS), medication modules, and modules for ordering tests and receiving test results, and some also have electronic modules for clinical documentation and booking.

In 2009, Central Denmark Region, one of the five Danish regions, decided to implement a comprehensive EHR at an entire hospital, to test its large-scale clinical applicability. The EHR had been developed by the regional administration and a software company over the preceding six years, and comprises modules for booking, ordering tests and receiving test results, prescribing and administering medication, patient administration, and documenting clinical work. The EHR modules are integrated, use the same database, and exchange information seamlessly, and since the modules encompass almost all functionality needed by health care professionals in their daily work, the EHR may be called "comprehensive". The medication, booking and ordering/receiving test modules had already been implemented at other hospitals in the region some years previously, but the PAS was to be replaced by a new module, and another entirely new module was also introduced, to replace all paper-based records documenting the work of physicians, nurses, occupational and physiotherapists, midwives, and so on. The existing picture archiving and communication systems for $\mathrm{x}$-rays and MR scans, microbiology lab reports system, and other electronic systems were not integrated into this version of the EHR, which is why it was labeled a "comprehensive", rather than a "complete" EHR. The EHR is based on structured data so that entries by all professions are primarily structured and linked to standard nomenclatures, so that, for example, the EHR automatically reports Diagnose Related Group codes to the National Board of
Health for statistical and reimbursement purposes. Free texts field exist, but most entries are done by ticking of radio buttons or check boxes.

This was the first time the region implemented this broad range of functionality, and earlier versions of the EHR had been heavily criticized by clinical staff because of slow performance and lack of functionality. At the same time, the region was to decide whether to continue or abandon the development of this EHR. Successful implementation of the EHR was crucial to Central Denmark Region, which had invested much capital in the development of this EHR, approx. 45 million Euro at this point. Depending on the results of an evaluation, the EHR was to be implemented at the region's other five hospitals, including a large university hospital. Once implemented, use of the comprehensive EHR would be mandatory for all health care staff in the region, amounting to approx. 10,000 different daily users and covering 1.17 million patients with registered data.

Randers Regional Hospital (RRH) was designated as the implementation site for testing the EHR's large-scale clinical applicability. RRH has a staff of approximately two thousand. The hospital has 360 beds, and admits 30,000 patients annually, of which 25,000 are acute cases. Yearly, the outpatient clinics treat 110,000 patients. The hospital is medium-sized, and ranks nationally as one of the most productive measured on treatments per staff. Implementation was scheduled to take place in three stages during February, March, and April 2010, and because of the region's need for a rapid evaluation, focus was on the Department of Internal Medicine and the Emergency Medical Ward, which participated in the first stage of implementation in February 2010. Between them, these departments employ about half of the personnel at the hospital.

Shortly before its implementation at RRH, the regional administration commissioned an evaluation of the EHR, with the broad aim of evaluating the EHR's immediate consequences to health care work, and to identify potential barriers to further enrollment. The Institute of Public Health, which is part of the region, and Aarhus University (Denmark) were chosen as evaluators, and established a steering committee that included six representatives of health care staff. The region commissioned and received the evaluation report, which became publicly available, but did not otherwise participate in the evaluation. The region's decision regarding further 


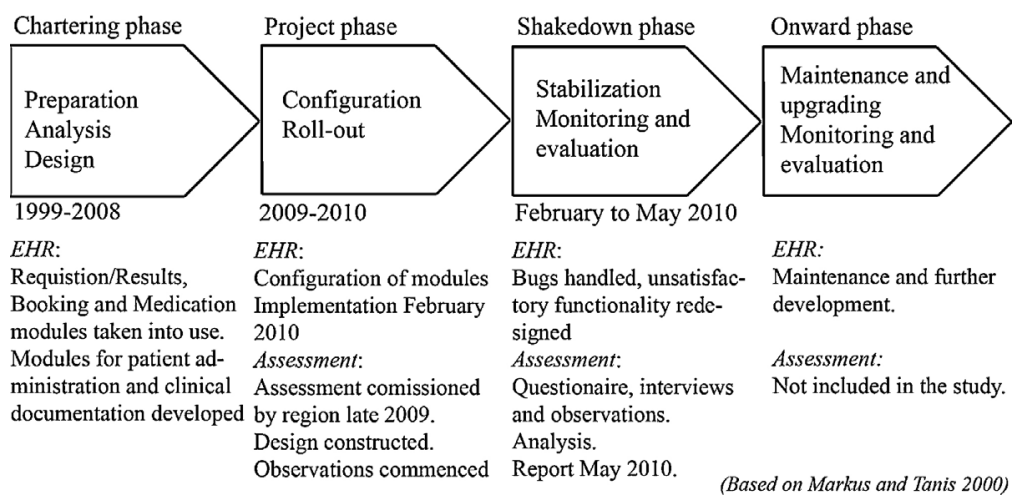

Fig. 1 - The implementation and evaluation process.

deployment was urgently needed, and the evaluation was to be handed in four months after implementation.

Few comprehensive EHRs have been adopted in European and U.S. hospitals [8,9]. In 2009, fewer than $3 \%$ of all U.S. hospitals had a comprehensive EHR, though Kaiser Permanente and the Veteran Health Administration being important exceptions have implemented such EHRs. Comprehensive EHRs may be found in European hospitals (e.g. at Hospital da Luz, Portugal) but there is no accurate estimate of their number. Few evaluations of comprehensive EHRs have been published, and are either based on interviews [10] or administrative data [11], so experiences with evaluation results and how to evaluate comprehensive EHRs are sparse.

This paper presents the results of an evaluation of a comprehensive EHR, shortly after its implementation at a medium-sized hospital. The paper makes three contributions to medical informatics: First, it provides an example of how comprehensive EHRs can be evaluated in the shake-down phase; second, it describes system performance data and experiences with the implementation of a comprehensive EHR, shortly after its implementation, third, it describes possible factors contributing to the relative success of the implementation.

\section{Methods}

Evaluation is a recommended part of the development and implementation of information systems and EHRs, to ensure system functionality, fit with work processes, and decisions regarding future design and deployment $[12,13]$. Evaluations may be either formative or summative. A formative evaluation is intended to improve the EHR by providing system providers with feedback, so changes may be made to the EHR. Formative evaluations can also guide subsequent implementations in other departments or at other hospitals. Summative evaluation is intended to demonstrate clinical or economic outcomes of the EHR in clinical routine [14]. A formative evaluation was chosen for this evaluation, since realization of the outcomes of the EHR may take up to a year to emerge fully, and does not come without frequent readjustment of the system, work processes, and organization. Prior research has also proven that formative evaluation immediately following implementation may be both necessary and valuable in this process [15]. In this case, the formative evaluation provided feedback to system providers to ensure the best possible implementation at other hospitals in the region by suggesting system upgrades and pointing out strengths and weaknesses in the implementation process at RRH.

Opportunity and time to develop a program theory for the evaluation were restrained, because the evaluation was commissioned just prior to implementation in late 2009, and because there was only a four-month window for data collection, analysis, and reporting between the first stage of implementation in February 2010, and the required submission of the evaluation in May 2010. This meant that the evaluation had to adapt to the implementation process by using the data and data sources available during this time frame. No ethical approval by an internal review board was required for this research. An overview of the implementation process and data collection period is presented in Fig. 1.

The updated DeLone and McLean framework for evaluating information systems (IS) success was chosen as the basis for the evaluation [16]. Since its introduction in 1992, a number of studies have empirically tested and validated relationships within the model, and discussed its practical applications [17-20]. The updated 2003 framework proposes that IS success includes seven dimensions: information quality, system quality, service quality, use, intention to use, user satisfaction, and net benefits [16] (see Fig. 2).

The evaluators chose the DeLone and McLean framework because it is well-validated, and its seven dimensions ensure an evaluation of the EHR's consequences for health care work

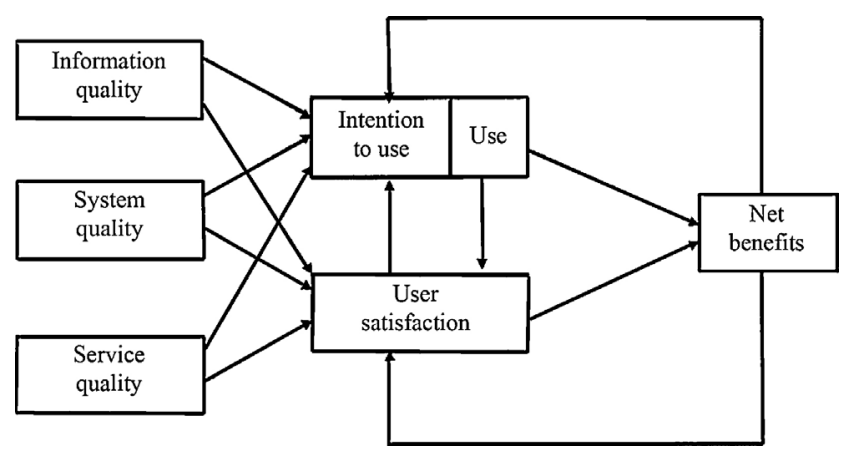

Fig. 2 - The updated DeLone and McLean framework for evaluating information systems success. 
over a wide, inclusive range of aspects. This reflected the region's and users' interest in the immediate effects of the EHR on health care work, and was well-received by all stakeholders.

The initially broad evaluation design was subsequently developed into a focus on the first four dimensions, namely "information quality", "system quality", "service quality", and "use". "Intention to use" was not investigated systematically, since in this case, use is mandatory, and because the focus of the evaluation was on whether the EHR supported staff work, and therefore on actual "use". However, to some extent, the way in which the EHR is put into use may depend on the attitude toward it. Before its implementation, staff had already had some experience of several modules of the EHR, and while some staff may have been satisfied with the EHR, physicians in particular were very critical of the system's slow performance and instability. A few months before implementation, the regional Chief Physicians' Council publicly demanded an abolishment of the system, or substantial improvement to it. On the other hand, a high level of user involvement just before implementation, and strong management commitment may have contributed to a more positive "intention to use". "Net benefits" were excluded, since they are presumed to remain unrealized at the time of evaluation, though staff expectations of future benefits will be reported. "User satisfaction" is addressed by the four dimensions already mentioned, since a significant amount of data in the evaluation is based on interviews and a user questionnaire.

The DeLone and McLean model does not specify the methods or parameters to be used, which must be selected on a case-by-case basis. With the aims of this evaluation in mind, we decided upon a mixed-method case study design, which also included triangulation of data, respondents and investigators (various educational backgrounds). Case studies are particularly suited to the study of phenomena over which the researcher has little or no control, the context of the phenomena under investigation is important, and the interest is in understanding what happens, why, and where [21-23]. A mixed-methods approach is recommended by several authors, owing to the diverse and diffuse effects of health informatics, and in order to combine results, to achieve a varied and profound understanding of the causal links involved in the implementation and use of IT in health care [14,24-29]. The mixed-methods case study approach was also applied because these kinds of studies can provide rich, nuanced information. A recent review of evaluation of health care IT recommends methodological pluralism, including both qualitative and quantitative methods [30]. Mixed-methods approaches usually investigate the implementation process, and primarily use different kinds of qualitative methods combined with surveys $[26,28,31,32]$. Westbrook et al. and Pluye et al. apply different approaches, respectively a "before and after design", and qualitative data combined with system data $[27,33]$.

This evaluation applies a case-based and mixed-methods approach, designed to be interactive and concurrent [34] (see Table 1).

Initially, documents describing the technical aspects of the EHR, the region's health care IT strategy, and previous evaluations were studied, to provide an understanding of EHR functionality, the context of implementation, and how others had evaluated EHRs. This was followed by meetings with stakeholders. Ethnographic observations were conducted before implementation to obtain an understanding of staff's everyday work situation and perspective (emic view), and were selectively focused, to obtain an understanding of work processes before implementation, and to suggest hypotheses for how the EHR might change these.

The evaluators decided to focus on four clinical groups: physicians and nurses (because they are central users of patient records), medical secretaries (because of the new PAS module), and physiotherapists (because the EHR meant a significant change to their documentation practices).

Two months after implementation, a paper-based questionnaire was distributed on-site to the four previously mentioned groups, which used the EHR as an integrated part of their work day. The objective was to obtain quantitative reliable data of user assessment, and it was designed around information, system, and service quality, used in the DeLone and McLean framework, and pilot-tested on eleven staff members and two of the IT staff before distribution. The phrasing and selection of question always involves a methodological tradeoff between following established standards, and adapting these to adequately fit the case at hand. The questionnaire for this evaluation complies with the overall definition of the dimensions in the DeLone and McLean framework, but was modified slightly, in response to system providers and users, in order to secure their acceptance of the evaluation design, and to be as relevant and comprehensible as possible to the work practices and common understandings of the four groups studied. While a validated instrument might have ensured a greater generalizability, the questionnaire was adjusted to improve validity [35] (the questionnaire is available as supplementary material). The questionnaire obtained a response rate of $63 \%$, which is slightly higher than comparable studies reporting user evaluations of EHRs, or their private sector counterparts (Enterprise Resource Planning systems (ERP)) $[15,36,37]$. Non-response bias was tested by prolonging an announced deadline of two weeks for completing the questionnaire in one week, and making t-tests for significant differences in the responses (in means and variances) on all items. No non-response bias was found. Data from the questionnaire was subsequently analyzed with a series of ANOVA tests, which provided a statistical test of whether or not the means of several groups were equal, in order to highlight issues across professions and departments that stand out relatively positively or negatively. This was done in Statistical Package for the Social Sciences (SPSS).

Concurrently with the questionnaire, we conducted thirteen individual, on-site, semi-structured interviews with staff from the four professions, to evaluate user assessments in depth and with a high degree of data validity. Interviewees were randomly selected from department rosters, and the interviews covered the same topics as the questionnaire. Individual interviews and open-ended questionnaire responses were analyzed in NVivo, a software program for qualitative analysis. The interviews were transcribed verbatim, and two researchers independently coded all individual and group interviews into significant themes. Coding was compared 
Table 1 - Overview of methods.

\begin{tabular}{|c|c|c|c|c|}
\hline Method & Purpose & Scope & Focus & Time \\
\hline $\begin{array}{r}\text { Ethnographic } \\
\text { observation }\end{array}$ & $\begin{array}{l}\text { - Inform design of } \\
\text { questionnaire and } \\
\text { interview guides } \\
\text { - Understanding of daily } \\
\text { use of patient records } \\
\text { - First-hand observation of } \\
\text { taking in use of the EHR }\end{array}$ & $\begin{array}{l}\text { - } 88 \mathrm{~h} \\
\text { - } 64 \mathrm{~h} \text { with the four } \\
\text { professions (physicians, } \\
\text { nurses, medical secretaries, } \\
\text { physiotherapists) } \\
\text { - } 10 \mathrm{~h} \text { : all expert user } \\
\text { meetings } \\
\text { - } 14 \text { h: all implementation } \\
\text { management group } \\
\text { meetings }\end{array}$ & $\begin{array}{l}\text { - Evaluation of use } \\
\text { - Taking EHR into } \\
\text { use } \\
\text { - Changes in work } \\
\text { due to EHR } \\
\text { - Spontaneous } \\
\text { evaluation of EHR }\end{array}$ & $\begin{array}{l}\text { Two months before } \\
\text { to two months after } \\
\text { taking in use of the } \\
\text { EHR }\end{array}$ \\
\hline Questionnaire & $\begin{array}{l}\text { - Quantitative data from } \\
\text { health care staff evaluation }\end{array}$ & $\begin{array}{l}\text { - } 387 \text { questionnaires } \\
\text { distributed } \\
\text { - } 244 \text { questionnaires } \\
\text { answered } \\
\text { - Response rate } 63 \% \\
\text { - } 67 \text { questions, } 4 \\
\text { open-ended }\end{array}$ & $\begin{array}{l}\text { - Screening staff } \\
\text { assessments for } \\
\text { information, system, } \\
\text { and service quality, } \\
\text { use of EHR and } \\
\text { expectations of } \\
\text { future net benefits } \\
\text { - Respondent } \\
\text { characteristics } \\
\text { (profession, ward, } \\
\text { age, etc.) } \\
\text { Screening staff } \\
\text { assessments of } \\
\text { taking the EHR into } \\
\text { use }\end{array}$ & $\begin{array}{l}\text { Months } 1-2 \text { after } \\
\text { implementing EHR } \\
\text { March } 2010\end{array}$ \\
\hline $\begin{array}{l}\text { Individual, } \\
\text { semi-structured } \\
\text { interviews }\end{array}$ & $\begin{array}{l}\text { - Qualitative data from } \\
\text { health care staff evaluation } \\
\text { - In-depth understanding } \\
\text { of EHR evaluation }\end{array}$ & $\begin{array}{l}\text { - } 13 \text { individual interviews: } \\
\text { - } 4 \text { physicians } \\
\text { - } 3 \text { nurses } \\
\text { - } 3 \text { physiotherapists } \\
\text { - } 3 \text { medical secretaries } \\
\text { - Total, } 715 \mathrm{~min} \\
\text { - Average } 55 \mathrm{~min} \\
\text { - Shortest/longest } \\
\text { 31/114 min }\end{array}$ & $\begin{array}{l}\text { - In-depth staff } \\
\text { assessments of EHR } \\
\text { with regard to } \\
\text { information, system, } \\
\text { and service quality } \\
\text { - In-depth staff } \\
\text { experiences of the } \\
\text { process of taking the } \\
\text { EHR into use } \\
\text { - Expectations of } \\
\text { projected net } \\
\text { benefits }\end{array}$ & $\begin{array}{l}\text { Months 1-2 after } \\
\text { taking in use of EHR }\end{array}$ \\
\hline Performance data & $\begin{array}{l}\text { - Quantitative performance } \\
\text { data } \\
\text { - Statistical performance } \\
\text { information }\end{array}$ & $\begin{array}{l}\text { - } 90 \text { th and 99th percentiles } \\
\text { for response time for } \\
\text { - } 10 \text { most-used } \\
\text { functionalities in EHR } \\
\text { - } 3 \text { central functionalities: } \\
\text { Login, Overview, Read } \\
\text { Record } \\
\text { - Number of critical errors }\end{array}$ & $\begin{array}{l}\text { Secondary data on } \\
\text { system quality } \\
\text { Extent to which: } \\
\text { - Response times } \\
\text { were within limits } \\
\text { set by the region } \\
\text { - Response times } \\
\text { showed a trend } \\
\text { toward stability } \\
\text { Number of critical } \\
\text { errors was stable or } \\
\text { decreased }\end{array}$ & $\begin{array}{l}\text { Month } 1 \text { before, to } \\
\text { Month } 2 \text { after taking } \\
\text { in use of EHR }\end{array}$ \\
\hline $\begin{array}{r}\text { Focus-group } \\
\text { interviews }\end{array}$ & $\begin{array}{l}\text { - Qualitative data on health } \\
\text { care staff evaluation of EHR } \\
\text { - Follow-up on issues } \\
\text { arising from questionnaire, } \\
\text { individual inter-views, and } \\
\text { performance data }\end{array}$ & $\begin{array}{l}\text { - } 7 \text { focus-group interviews } \\
\text { - Physicians, nurses, } \\
\text { medical secretaries, } \\
\text { physiotherapists, region's } \\
\text { IT department, hospital's IT } \\
\text { department, } \\
\text { implementation group } \\
\text { - Total } 614 \text { min } \\
\text { - Average, } 88 \text { min } \\
\text { - Shortest/longest } \\
69 / 118 \text { min }\end{array}$ & $\begin{array}{l}\text { Exploration of staff } \\
\text { and system provider } \\
\text { assessments of } \\
\text { information, system, } \\
\text { and service quality, } \\
\text { use and future } \\
\text { expectations of net } \\
\text { benefits }\end{array}$ & $\begin{array}{l}\text { Month } 2 \text { after taking } \\
\text { in use of EHR }\end{array}$ \\
\hline
\end{tabular}


and differences resolved through discussion between the two coders.

Daily system performance data were extracted from the EHR to supplement user assessments with quantitative reliable data. Data were analyzed by use of statistical process control, to assess average response time, critical system errors, and to evaluate their fluctuations during the implementation period.

Subsequently, we conducted on-site focus-group interviews to obtain an in-depth, follow-up elucidation of the preliminary results from the questionnaire, individual interviews, and performance data. A focus-group interview was conducted for each of the four clinical professions. At the same time, focus group interviews with two IT departments and the implementation team were conducted, to gain insight into system provider assessments of the implementation process and the EHR.

Throughout the implementation process, ethnographic observations were made, to give the evaluators an understanding of the daily work of staff, and their use of health records. Notes were taken while observing staff and meetings, then written out as extended texts, and coded into significant patterns.

Assessment by users of the EHR is central to this evaluation. However, this evaluation also includes data generated by other sources, such as ethnographic observation, assessments from system providers, and performance data extracted from the EHR. This mix of methods made it possible to triangulate data, by validating these (e.g. evaluation of performance in questionnaire, interviews and system performance data), and enabling a more nuanced interpretation of results (e.g. dissatisfaction of medical secretaries in questionnaire was elucidated in interviews) [14].

\section{Results}

In the interviews, the data pointed toward a generally positive, though not uncritical assessment of the EHR across departments and professions. Although staff assessed the EHR to not entail less work, it was seen as supporting their tasks, and they had high expectations of its benefits to patients, staff, and the hospital in the future. A summary of the results of the questionnaire across professions and the two departments also reflects this general satisfaction (Table 2). (The questionnaire comprised 61 questions, to some of which multiple answers were possible, resulting in 87 possible answers.)

From Table 2, it can be seen that generally, responses are greater than " 3 " (neutral), except for questions 33 and 34 , regarding reduction of tasks. The researchers and system providers were surprised to see that the expectations of future benefits were very high (questions 37-39), at a time when staff had just acquired the skills for using the EHR, and new work practices were not yet fully established.

However, the observations and interviews highlighted a number of critical issues, and physicians and medical secretaries stand out as being least positive, for reasons we describe below. In the following sections, we explore the results in greater detail, and present issues on which specific professions stand out for their relatively positive or negative response.

\subsection{Information quality}

"Information quality" concerns whether the data in the EHR are relevant, comprehensive, precise, and provide an adequate overview of clinical work [16]. Since clinicians themselves enter data, the focus will not be on precision and comprehensiveness, because this is presumed on the basis of the clinicians' professionalism. Instead, the focus is on staff experience of whether they can enter and find data, and establish an overview of patients.

Table S1 presents the statistical significant results of the questionnaire items concerning information quality across professions (all ANOVA tests on the information quality items can be found in the supplementary material). Significant differences were found in the assessments between physicians and physiotherapists of how up to date data in the EHR are. Whereas physiotherapists themselves entered data into the EHR, and therefore had no problems with updated data, physicians relied on medical secretaries to transcribe their dictation into the EHR. Throughout the implementation period, there were significant delays in transcribing physician dictation, because of a more cumbersome interface and slow performance of functionalities crucial to medical secretaries.

Another theme that showed statistically significant differences in the questionnaire was the assessment of the ordering of information. Individual and group interviews conveyed the general conclusion that nurses were satisfied with options for entering and finding data. However, observations and individual and group interviews with physicians revealed that some were significantly dissatisfied with the new structuring of their dictation. Previously, these comprised one, coherent text, but were now structured into specific fields, such as, "status", "diagnosis, "prescription", and "plan", in order to facilitate the accumulation of patient data, for example, diagnosisrelated data. The physicians argued that for patients with multiple diagnoses, this structuring meant that diagnoses were separated from prescriptions and plans, fragmenting the underlying logic interconnecting them. Observation and interviews also revealed that some medical secretaries found the structure of the new PAS module confusing.

Although not significant in the questionnaire, establishing an overview of patient information was a recurrent theme in interviews with physicians. The comprehensive EHR has two special functionalities designed to provide overviews. "Read Record" accumulates information from notes, similar to a summary, and can filter these in customized formats for individual departments or groups of professionals. While nurses were generally satisfied with Read Record, some physicians were dissatisfied with it, and argued that there was too much irrelevant information, since nurses' and physiotherapists' notes were included in the cross-professional EHR. "Overview" is a highly flexible functionality that displays selected information in one to twelve different fields, depending on the needs and choices of the particular department or group of professionals. However, interviews revealed that frequency of use and evaluations of Overview were particularly varied, and 
Table 2 - Descriptive statistics from questionnaire across all professions and departments.

\begin{tabular}{|c|c|c|c|}
\hline & $n$ & Mean & S.D. \\
\hline \multicolumn{4}{|l|}{ Information quality } \\
\hline 10. It is easy to establish an overview in the EHR & 242 & 3.32 & 1.05 \\
\hline 11. It is easy to find information in the EHR & 242 & 3.50 & 0.89 \\
\hline 12. Information in the EHR appears orderly and easy to read & 240 & 3.53 & 1.01 \\
\hline 13. Information in the EHR is always updated & 240 & 3.94 & 0.92 \\
\hline 14. The EHR provides me with the information I need for my work & 238 & 3.67 & 0.94 \\
\hline 15. It is easy to document information the right places & 238 & 3.32 & 0.99 \\
\hline \multicolumn{4}{|l|}{ System quality } \\
\hline 18. It has been easy for me to learn how to use EHR & 240 & 3.94 & 0.91 \\
\hline 19. Response time for login is satisfactory & 239 & 4.15 & 0.91 \\
\hline 20. EHR responds rapidly and satisfactorily when shifting between screens & 239 & 4.04 & 1.00 \\
\hline 21. EHR is stable to a satisfactory degree (crashes seldom) & 238 & 3.93 & 0.94 \\
\hline 22. Login is easy in the HER & 239 & 4.61 & 0.70 \\
\hline \multicolumn{4}{|l|}{ Service quality } \\
\hline 24. I am satisfied with the support I received the first 14 days after implementation & 238 & 4.34 & 1.11 \\
\hline 25. I am satisfied with the support I received after the first 14 days & 233 & 4.21 & 1.07 \\
\hline 26. I am satisfied with the available user guides and help functions & 224 & 3.66 & 1.09 \\
\hline \multicolumn{4}{|l|}{ Use } \\
\hline 31. Generally, the EHR supports my work procedures & 233 & 3.91 & 0.83 \\
\hline 32. Implementation of the EHR entails new tasks for me & 231 & 3.25 & 1.32 \\
\hline 33. Implementation of the EHR has meant that I have handed over tasks to others & 226 & 2.26 & 1.34 \\
\hline 34. The EHR has replaced paper records, but has also entailed new documentation on paper & 227 & 2.47 & 1.31 \\
\hline 35. Generally, the EHR has made my work easier & 236 & 3.50 & 1.12 \\
\hline \multicolumn{4}{|l|}{ Expectations to future net benefits } \\
\hline 37. I expect the EHR to benefit patients in the future & 235 & 4.67 & 0.61 \\
\hline 38. I expect the EHR to benefit staff in the future & 236 & 4.67 & 0.56 \\
\hline 39. I expect the EHR to benefit the hospital in the future & 232 & 4.68 & 0.55 \\
\hline
\end{tabular}

the conclusion was that careful setup in close cooperation with staff was required, for it to become usable.

\subsection{System quality}

"System quality" addresses whether a system has the required functionality to support the work in question, and involves issues such as functionality, integration with other systems, performance, stability, and ease of use [16].

In general, individual and group interviews conveyed a consensus that the integration of various functionalities in the comprehensive EHR, such as medication information, physicians', nurses', and physiotherapists' notes, patient data, and the requisition and results of tests, is beneficial. However, physicians lamented the lack of integration with PACS (Pictures Archiving and Communication System for MR scans, $\mathrm{X}$-rays, etc.), the microbiology laboratory report system, and other systems. As mentioned previously, there were demands - primarily from physicians - for the two overview functionalities, Read Record and Overview, to be further developed. From the interviews, we found that medical secretaries felt that the new PAS required too many mouse clicks.

Table S2 presents the statistical significant results of the questionnaire items concerning system quality across professions (all ANOVA tests on the system quality items can be found in the supplementary material). Prior to implementation, physicians had severely criticized performance (i.e. system response time and critical errors), in the public media. Efforts by the IT departments involved seemed to resolve performance problems, and in the questionnaire system providers were pleased to see that in general staff was satisfied with login, system stability, and response times. Response times when switching between screens were perceived as too slow by the medical secretaries. Some physicians were outspokenly dissatisfied with incidents of slow performance, the major ones being slow performance on the second day of implementation, lasting half a day, and Read Record responding slowly on the seventh to ninth days of implementation (Friday to Sunday). In the interviews, the physicians stated that poor system performance was particularly unsatisfactory, since they must often make critical decisions about patient medication and plans, and therefore have a low tolerance for system unavailability.

Results from system performance data indicate that, for the most part, response times for the measured functionalities are below the maximum acceptable response-time percentiles defined by the region. Table 3 shows the 90th and 99th percentiles of the response times of the twelve most used functionalities in the EHR, for the first three months following system implementation, compared to the thresholds defined by the region.

Statistical process control (SPC) analysis supports these results. The idea of using SPC is that response times will exhibit variation because of the amount of data requested by the user, and the number of users on the system simultaneously, for example. If response times are stable, or said to be in control, variability is found to exist within a predictable statistical range. If response times are unstable or out of control, 
Table 3 - System performance data: response times.

\begin{tabular}{|c|c|c|c|c|c|}
\hline \multirow[t]{2}{*}{ Functionality } & \multirow{2}{*}{$\begin{array}{c}\text { \# times used } \\
\text { N }\end{array}$} & \multicolumn{2}{|c|}{ Threshold percentiles } & \multicolumn{2}{|c|}{ Actual percentiles } \\
\hline & & 90 & 99 & 90 & 99 \\
\hline Residential address of the patient & 463,995 & $4 \mathrm{~s}$ & $6 \mathrm{~s}$ & $1.0 \mathrm{~s}$ & $1.7 \mathrm{~s}$ \\
\hline Display results & 351,959 & $2 \mathrm{~s}$ & $4 \mathrm{~s}$ & $1.3 \mathrm{~s}$ & $2.4 \mathrm{~s}$ \\
\hline Locate patient in the hospital & 190,474 & $4 \mathrm{~s}$ & $6 \mathrm{~s}$ & $3.0 \mathrm{~s}$ & $6.8 \mathrm{~s}$ \\
\hline Display patient plan & 175,445 & $4 \mathrm{~s}$ & $6 \mathrm{~s}$ & $2.8 \mathrm{~s}$ & $4.6 \mathrm{~s}$ \\
\hline Administer single dose of medicine & 169,438 & $2 \mathrm{~s}$ & $4 \mathrm{~s}$ & $0.5 \mathrm{~s}$ & $0.9 \mathrm{~s}$ \\
\hline Read Record & 166,759 & $4 \mathrm{~s}$ & $6 s$ & $5.8 \mathrm{~s}$ & $14.7 \mathrm{~s}$ \\
\hline Overview over period & 162,999 & $4 \mathrm{~s}$ & $6 s$ & $0.7 \mathrm{~s}$ & $1.4 \mathrm{~s}$ \\
\hline Cumulated results for a given patient & 155,070 & $4 \mathrm{~s}$ & $6 s$ & $1.2 \mathrm{~s}$ & $4.6 \mathrm{~s}$ \\
\hline Overview of medication for a given patient & 149,787 & $4 \mathrm{~s}$ & $6 \mathrm{~s}$ & $0.9 \mathrm{~s}$ & $2.0 \mathrm{~s}$ \\
\hline Prescription overview for a given patient & 145,034 & $4 \mathrm{~s}$ & $6 s$ & $1.0 \mathrm{~s}$ & $2.1 \mathrm{~s}$ \\
\hline Login & 82,465 & $12 \mathrm{~s}$ & $28 \mathrm{~s}$ & $3.5 \mathrm{~s}$ & $8.4 \mathrm{~s}$ \\
\hline Comprehensive overview of a given patient & 50,014 & $4 \mathrm{~s}$ & $6 s$ & $5.2 \mathrm{~s}$ & $11.1 \mathrm{~s}$ \\
\hline
\end{tabular}

Percentiles for response times (in seconds) for the 12 most used functionalities between February 1st and April 30th 2010. Times above threshold limits defined by the region are shadowed.

measured values will deviate beyond this range. With the help of assumptions from the statistical distribution of response times, it is possible to formally test whether response times deviate from predictions [38].

Fig. 3 shows an example of the typical pattern of response times for most of the percentiles during the first three months following implementation, together with the control limits. Response times were under control, but increased during the first two and a half months, probably because of increased numbers of users and functionality, after which they showed signs of decreasing.

\subsection{Service quality}

"Service quality" addresses the support available to users of a system. User training was included in this evaluation, as it was regarded as possibly providing important information for future implementations [16].

Training was based on a brief, guided introduction preceding implementation, rather than costly, complicated, and extensive hands-on training. During the first fourteen days, support staff - easily recognizable in green jackets - was available to the various departments around the clock. In individual and group interviews, staff expressed a desire for more handson training before implementation, and indicated that the first days of use had been stressful. However, they also stated that taking the system into use had been easy, and that technical support had been highly satisfactory. Overall, the training and support strategies seem to have been very satisfactory, as confirmed by the questionnaire (Table S3).

The observations suggest that user satisfaction with service quality may have been enhanced by the IT department's cooperation with the system providers in providing quick updates to the EHR. This included correction of critical bugs, and an update of the medical secretaries' transcription functionality, enabling the secretaries themselves to choose among a number of fonts and font sizes, instead of the one font initially provided, which the secretaries found too small and difficult to read, slowing transcription. Another quick update was made to Read Record, to more precisely filter information included there, to meet the needs of physicians, after they complained that too much information from other professions was included. Additionally, staff from the IT department met with support staff, which were present daily on the wards during the first fourteen days after implementation, received information regarding hospital staff problems with the EHR, and were often able to adjust the EHR, or suggest a solution that support staff could bring back to the wards. Hence, in certain situations, the IT department and the implementation organization were able to be highly responsive to hospital staff, though a number of bugs and necessary updates took months to facilitate.

However, Table S3 also reveals that physicians and medical secretaries remained less satisfied with all service-quality items than did nurses and physiotherapists. As mentioned previously, physicians and medical secretaries had unsatisfactory experiences with functionalities central to their work. In group interviews, system providers attributed the relatively low levels of satisfaction among these two groups to these experiences.

\subsection{Use}

Table S4 presents the statistical significant results of the questionnaire items concerning use across professions (all ANOVA tests on the use items can be found in the supplementary material). Generally, staff felt that the EHR supported their work tasks, and that the EHR did not require new workrelated tasks. Medical secretaries, who had problems with the PAS, proved to be the exception, and they proposed several improvements that were incorporated in the subsequent software upgrade of the EHR.

In the interviews, there was a general satisfaction with the accessibility of information, which the EHR facilitated, and its adequacy for work tasks. Physicians appreciated the ease of retrieval of data on daily measurements of patient blood pressure, pulse, and temperature, and appreciated not having to look for records, since these were available wherever there was computer access. Nurses and physiotherapists appreciated that they could now enter and find information in one place, rather than in several documents and records, as before. Although medical secretaries found that their work 


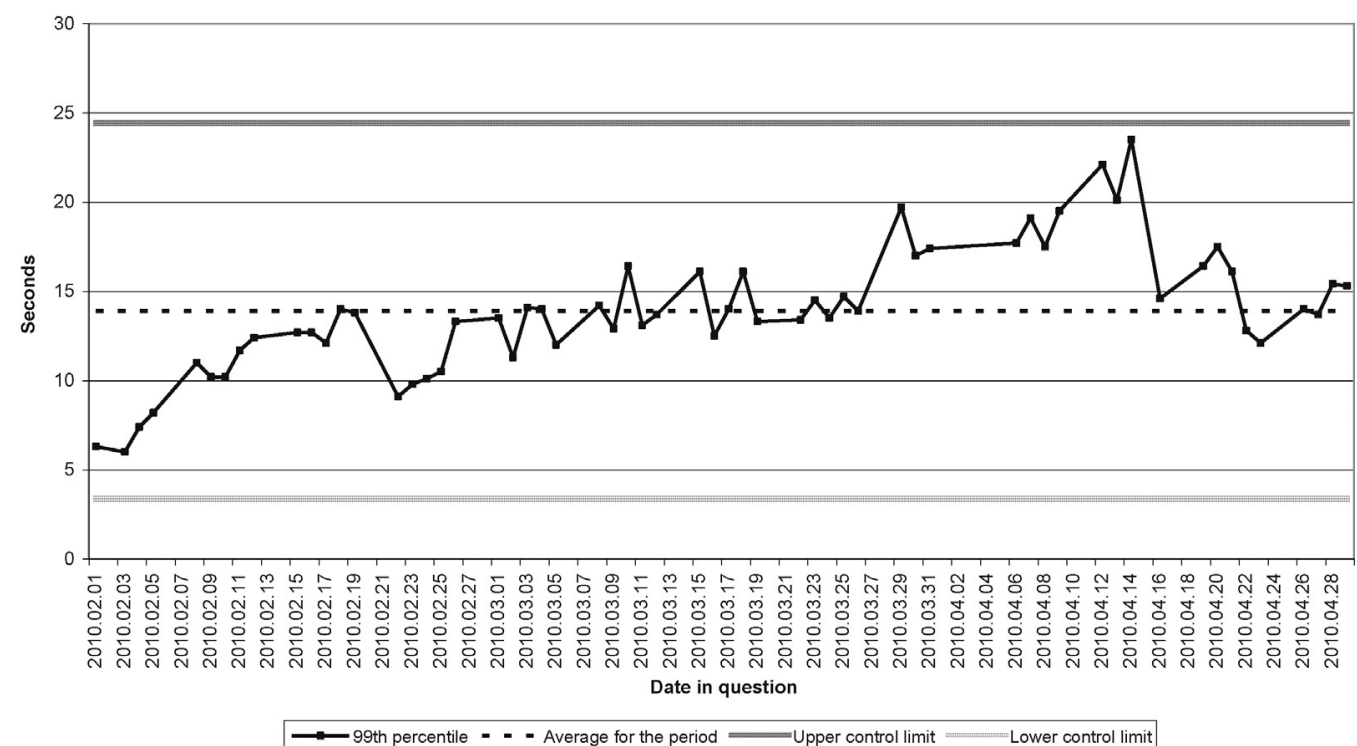

Fig. 3 - Ninety-nine percentiles for response times for the functionality "Read Record". The typical pattern is that response times are in control although increasing during the first two and half month where after there are signs of decreasing response times.

had become more difficult and cumbersome, observation indicated the benefit of medical secretaries no longer having to keep track of records moving within and between departments and the archives, or spending time locating them. Additionally, physicians themselves could now enter codes for diagnoses and Diagnosis Related Groups, reducing the medical secretaries' workload, though they sometimes still need to do this on the basis of physicians' dictation, as before. Furthermore, physiotherapists' entries were made in standardized formats, so that coding their services for reimbursement became automatic (clicking a radio button or entering text in a field activates a specific code), a task previously carried out by medical secretaries.

\subsection{Overall no difference between departments}

A general characteristic of the results of the questionnaire should be noted: No significant differences were observed in mean values of the items in the questionnaire across the two departments, which is why no ANOVA tests administered to departments are presented. This may be unsurprising with regard to physicians, since they work in both departments. However, for nurses, medical secretaries, and physiotherapists, this suggests either that profession is more important than the department in which one is employed, or that the implementation of the EHR had been similarly successful in both departments.

\section{Discussion}

The results of the evaluation were impatiently anticipated, since the region had to decide whether to implement the EHR at its other five hospitals, or abandon the ten-year-long development project entirely. Furthermore, physicians had been severely critical of the poor performance of previous versions of the EHR, prior to implementation of the EHR version in focus in this paper. Therefore, the generally positive evaluation results were a welcome relief to the region, system providers, and $\mathrm{RRH}$, who had been front-runners in EHR implementation. However, this evaluation can also be of interest to the research community in medical informatics, since evaluations of this kind of complex EHRs are rare: The EHR is cross-professional (comprising all staff e.g. physicians, nurses, medical secretaries, and physiotherapists), cross-departmental (a Department of Internal Medicine and an Emergency Medical Ward), and involves structured data that challenge the underlying logic more easily made explicit in narrative data $[39,40]$. The paper provides an example of how to evaluate comprehensive EHRs, and how this can be achieved in the shake-down phase. Furthermore, the overall positive results may suggest factors contributing to success.

Despite the overall satisfaction, the evaluation also underscored the pertinence to system providers and the region's decision-makers of the need to integrate the EHR with other IT systems (picture archiving and communication systems for Xrays and MR scans, and the microbiology lab reports system): Hospital staff, especially physicians, complained that having to initiate and work with these additional systems along with the EHR was burdensome, and slowed their work. Indeed, immediately following this evaluation, the region made plans to integrate these systems with the EHR within a year. With this, the EHR would approach being a "complete" EHR. Some paper documents will probably continue to be used, since electrocardiograms are still printed on long strips of graph paper, and to assist memory, hospital staff take traditional notes on the patients in their care.

Successful implementation of EHRs generally requires satisfaction on the part of staff [41]. In this study, staff at the two departments was generally satisfied, and we have presented 
the major themes associated with this satisfaction. Earlier studies on satisfaction with the implementation of EHRs in both hospitals and primary care concluded that it is possible to achieve a general level of satisfaction among physicians and nurses, but that there may be concerns about changes in documentation practices and presentation of information in the EHR, or about interpersonal communication [10,42-44]. At least one study has also indicated that groups of physicians and medical specialties react differently when EHRs are implemented [42], making it difficult to implement "a-oneEHR-fits-all" approach across professions and departments. In this case, functionality and presentation of data was configured differently to different professions, which may have contributed to the general satisfaction, and the dissatisfaction of physicians and medical nurses pertained to functionality specific to them. This evaluation is consistent with other evaluations of comprehensive EHRs, in that results show an appreciation of the accessibility of data, and a concern that documentation takes longer [10]. However, it could not include clinical or economic data such as the number of adverse events or productivity, since it was conducted immediately after implementation [11].

The DeLone and McLean model has become one of the most cited and used models for evaluating information systems $[45,46]$. Based on this model, several evaluations of health care systems have also been conducted (e.g. $[47,48])$, as has a systematic review of health care studies [49]. It has been argued that the model does not sufficiently consider contextual factors (e.g. organization culture and structure) [50]. On the other hand, one study argued that "The IS success model, though, has been criticized for focusing on information technology (IT) and system quality ... remains the most logical way of organizing the various factors that have been measured to determine the effectiveness of EMR systems in a coherent manner." ([48, p. 659]).

We chose to use the model because it had been validated by other studies, and combined a comprehensive scope, with regard to the different aspects that may influence information system success, and a relatively simple model, using only six dimensions. However, while apparently simple, operationalizing the model into a research design, interview guide, and survey requires identifying the relevant aspects to be evaluated within each dimension. Furthermore in the interview guide and survey these aspects must be translated into concepts relevant and meaningful to hospital staff. As such, the model merely provides a framework within which substance and specifics must be developed, in order to make the model functional within the health care domain. Though all the authors have extensive knowledge of the health care domain, identifying aspects and relevant concepts was found to require some effort, and the testing of interview guides and the questionnaire before deployment, to evaluate the set of questions and wording, is strongly recommended. While the DeLone and McLean model is valuable for its comprehensiveness and relative simplicity, its usefulness in the area of health would be improved, if the variables of measurement within its six dimensions could be made more specifically relevant to the domain, and a tool box of different questionnaires and surveys be developed. While health care itself is a varied and complex domain, this would simplify the development of research designs and evaluations. This evaluation provides one example of how to conduct evaluations in health care based on the updated DeLone and McLean model.

Evaluating EHRs and other complex, health-care information systems, is inherently difficult $[12,13]$. IT systems, and the work processes and organizations of which they are a part are complex and continuously changing. Systems are frequently updated, and staff constantly change their workflow. Therefore, establishing causality between the implementation of an EHR and its effects is challenging [29,41]. Evaluation during the shakedown phase is especially difficult, because new ways of working and the organizational set-up may not yet be optimally adapted to the new technology. However, evaluation may be necessary to inform system providers and political decision-makers, to effect changes in the infrastructure, the EHR, and funding, and hence facilitate subsequent developments $[13,15]$. With the possible exception of severe performance problems, major changes should probably be left until the organization and patterns of use have stabilized around a new EHR, while many small adjustments may be made during shakedown. In any case, changes should be done on an informed basis, and here, systematic evaluations can be relevant and informative. Since evaluations take time and effort, if conducted during the shakedown phase, they should be designed carefully, since they may be overtaken by other developments in this rapidly evolving phase. In this case, a major political decision regarding whether or not to implement the EHR at other hospitals had to be made four months after implementation, and the scope and depth of the evaluation had to be designed accordingly. During this evaluation several adjustments to functionality and performance were made (e.g. the functionality of physicians and medical secretaries) and work practices and the organization still adapting, but nonetheless the evaluation provided an early indication of the clinical applicability of the EHR.

\subsection{Success factors}

A significant contributing factor to the success of this EHR is probably the set of characteristics of the EHR itself, since it is highly configurable, and may be extensively adjusted for different groups of staff and departments. However, earlier studies have shown that successful implementation of EHRs also depends on a wide range of contextual and organizational factors $[13,16,51]$, and hence the positive evaluation results merit further discussion. Based on our knowledge of previous versions of the EHR [52,53], and having followed the implementation process of the present version since the commission of the evaluation at the end of 2009, we propose the following factors as contributing to the successful outcome.

\subsubsection{Qualified in-house implementation team}

Some years previously, the hospital established an implementation organization, while implementing the medication, booking, and ordering/results modules. Therefore, RRH had a smoothly functioning, experienced, and highly qualified inhouse implementation team.

Based on previous experience with the implementation of EHR modules, the team, together with management and system providers, could plan the implementation process, based 
on solid insight into the hospital's organization and staff, and choose a new support model (supporter presence on wards around the clock during the first two weeks) that helped users almost on the spot, and enabled rapid feedback from users to the team. Since the team was responsible for configuring the system with users, the team had detailed knowledge of the system's functionality, and could quickly respond to user feedback. All in all, this probably contributed to high service quality during implementation.

\subsubsection{Pre-implementation optimization of hardware and network}

Prior to, and during the implementation of the EHR system, the IT department continuously upgraded and optimized computers, cables, and wireless networks, and identified the need for improvements in light of anticipated changes in workflow and system load. On its part, the region worked on optimizing performance and stability, which had previously been severely criticized by physicians and the regional Chief Physicians' Council. All things considered, this meant that the EHR's performance and stability were much improved prior to implementation, which probably contributed to good "system quality".

\subsubsection{Management support}

Hospital management fully supported the implementation of the EHR, and was willing to invest the resources necessary for successful implementation. This probably influenced staff "intention to use": Though system use was mandatory, management support probably encouraged those supportive of the $\mathrm{EHR}$, and may have pushed its critics into reluctant acceptance of the EHR.

\subsubsection{High degree of user involvement}

The hospital's management and implementation organizations decided on a strategy for development and implementation with a high degree of user involvement. Before and during the implementation, newsletters were issued, containing information from management and the IT department, and interviews with staff involved in the implementation. The extent to which staff experienced this involvement as sincere and constructive may have enhanced commitment to the EHR implementation, and strengthened intention to use.

\subsubsection{Configuration of flexible EHR}

Users were extensively involved in configuring the flexible EHR to match their needs and requirements. This involved specifying the content and on-screen layout for particular groups of staff (e.g. physicians, nurses), specialties and processes (e.g. admittance and discharge). In addition to possibly enhancing the commitment of those involved, this user configuration of the EHR might also have contributed to information quality, since entering and finding data, and providing an overview were formatted by staff representatives with professional insight.

\subsubsection{Users already familiar with some EHR modules}

The employees at the hospital were already familiar with the booking, requisition/result, and medication modules, which had been implemented by the hospital some years previously.
Since the implementation was not a complete shift from a paper-based to an electronic record, this might have decreased resistance to implementing the EHR, and facilitated the use of new functionality, since staff was already accustomed to with working with IT. Hence, both intention to use and use may have benefited from this.

\subsubsection{Suspension of productivity demands}

The region allocated additional funding and suspended productivity demands during the year of the EHR implementation. This reduced pressure on health care staff and administration during and implementation and the period immediately following, and providing time for learning to work with the EHR. This may have influenced intention to use, use, and satisfaction.

\subsubsection{Need for success ensures cooperation between central actors}

Proving the value of ten years of investment and development was particularly important to the region and the EHR provider, but also to the hospital, since further deployment depended on a positive outcome. Cooperating for success was important to all. The implementation management group, consisting of hospital management, vendor representatives, and heads of the wards involved in the implementation, met daily during the first week, and then weekly during the two months immediately following implementation. The group was eager to respond quickly to critical problems, and in some cases to adjust the EHR or provide updates within days to address complaints by hospital staff (e.g. regarding the fonts in the medical secretaries' transcription functionality, or the filtering of information in Read Record, for physicians. See Section 3.3). The pressure and willingness to cooperate led to improved system quality and information quality, as well as a capacity to be responsive to and supportive of staff, thereby improving service quality.

\subsection{Strengths and limitations}

The main strength of this evaluation is the mix of methods that allowed triangulation of data and allowed for a nuanced understanding of results. While assessment by users is a key aspect in this evaluation, it also includes data generated from ethnographic field observations, assessments by system providers, and performance data. Ethnographic field observations provided information close to everyday practice at the hospital and, with other sources of information, informed the structuring and wording of the questionnaire. Individual interviews provided data with high validity brought forward what counted as major concerns to the interviewees, and the reliability of results from these could be checked through the questionnaire. The quantitative results from the questionnaire could be elucidated and validated in the focus group interviews, and this explained, for example, the physicians' and medical secretaries' dissatisfaction. Quantitative reliable data on system performance could be compared with results from questionnaire, and interviews and system [14].

One limitation of the evaluation is that the majority of data were generated shortly after implementation, during a time period in which users were still adapting to the system, and its 
ongoing implementation in the remaining departments of the hospital also changed work processes. Nonetheless, a robust evaluation was made and fulfilled the purpose of informing the region's decision making. However, follow-up or longitudinal studies are recommended when evaluating EHRs [29].

Another limitation is that a significant amount of the data was based on staff assessment (interviews and questionnaire). One could argue that the main dimension of the DeLone and McLean model that was evaluated in this study was "user satisfaction", and that this narrows the scope of the study, since this offers little explanation of what contributed to the levels of satisfaction. However, when the use of an information system is mandatory, measuring user satisfaction is an especially useful indicator of IS success, if it also includes items of system, information, and service quality, rather than measuring only general user satisfaction [54].

We do not know the extent to which the attitudes toward the EHR before implementation influenced the evaluation results, positively or negatively. "Intention to use" was not investigated systematically, because use was mandatory, and the evaluation focused on actual use. While physicians were particular critical of the EHR before implementation, several factors, outlined above, probably contributed to the change in attitude of the formerly skeptical: Improved performance and stability may have been particularly significant aspects.

Finally, the questionnaire was not based on a validated format, which may have decreased the generalizability of the results, but this evaluation instead aimed for validity (actually measuring the phenomena, e.g. staff and system providers' assessments of the EHR). The questionnaire seemed to have achieved this aim, since few complaints of incomprehensibility emerged during the interviews, though the terms of a subsection (question 30 ) turned out to be only partially relevant to the clinicians. This subsection requested an assessment of whether the EHR supported particular tasks. However, since the same questionnaire was used for all four professions, some tasks were not relevant to some professions.

\section{Conclusion}

We have presented a formative evaluation of a comprehensive EHR based on a mixed-methods case study, designed to be interactive and concurrent, and conducted in two hospital departments, based on the updated DeLone and McLean framework. The evaluation was based on system performance data, a questionnaire, single-person and group interviews, and ethnographic observation. It focused on four selected groups: physicians, nurses, medical secretaries, and physiotherapists. Additionally, focus group interviews with two IT departments and the implementation team were conducted. Few comprehensive EHR systems have been implemented worldwide, and none, according to our knowledge, has been evaluated systematically immediately after implementation.

The implementation entailed changes in work processes, which were challenging for both clinicians and medical secretaries. Overall, the level of satisfaction was positive, which is remarkable considering the cross-professional and crossdepartmental nature of the EHR, as well as the timing
Summary points

What was already known

- Evaluation during the shakedown phase of implementation is difficult, but may be necessary.

- Few evaluations of comprehensive EHRs have been conducted.

- Comprehensive EHR systems are difficult to evaluate, owing to their complexity, and because various professions use them.

- Because EHRs are complex, mixed-methods approaches are recommended.

- The updated DeLone and McLean framework has been used to measure information systems success.

What this study added

- Evaluation during the shakedown phase is feasible, and results may inform the political decision-making process.

- Comprehensive EHRs may be evaluated using the DeLone and McLean framework, which provides a good structure for reporting data from mixed-methods approaches.

- Using the DeLone and McLean model requires defining which aspects of the dimensions are relevant to a given case, and choosing the methods with which to evaluate these aspects (questionnaire; interviews; system data, etc.).

- Building up a knowledge base for different applications of this model in health care could be beneficial.

of the evaluation, shortly after implementation, when new work routines and system performance had not yet stabilized. In addition to the flexibility and suitability of system functionality, we propose that an experienced implementation organization, the upgrade of hardware and network, management support, a high degree of user involvement, and the allocation of necessary funding for the implementation effort were factors contributing to the positive outcome.

Evaluating IT systems shortly after implementation is difficult, because users and work practices are in a state of change, and the IT system may be subject to modification. Nonetheless, we believe we have shown that it is possible to conduct a broad, nuanced formative evaluation that may provide an early indication of the applicability of a large IT system. The updated DeLone and McLean framework was useful in the design of the evaluation of the EHR, and allowed methodological flexibility. The mixed-methods case study suited the situation and allowed for both investigative and qualitative methods, and the evaluation design was accepted by staff, system providers, and political decision makers. The evaluation informed the region's decision makers, regarding whether or not to implement the EHR system throughout the rest of the region. 


\section{Authors' contributions}

All three authors have contributed equally to the generation of data, analysis of data and writing of this article. However, individual author has specifically contributed to the following: ethnographic fieldwork was conducted by Claus Bossen; summary of quantitative survey and analysis of system performance data were conducted by Flemming Witt Udsen.

\section{Conflict of interest}

The authors have no conflicts of interest.

\section{Acknowledgements}

Sincere thanks to everyone who took time and effort to contribute to the evaluation.

\section{Appendix A. Supplementary data}

Supplementary data associated with this article can be found, in the online version, at http://dx.doi.org/10.1016/ j.ijmedinf.2013.05.010.

\section{REFERENCES}

[1] E.S. Berner, D.E. Detmer, D. Simborg, Will the wave finally break? A brief view of the adoption of electronic medical records in the United States, J. Am. Inf. Assoc. 12 (1) (2005) 3-7.

[2] C. Chantler, T. Clarke, R. Granger, Information technology in the English National Health Service, J. Am. Inf. Assoc. 296 (18) (2006) 2255-2258.

[3] W. Dorda, G. Duftschmid, L. Gerhold, W. Gall, J. Gambal, Austria's path toward nationwide electronic health records, Methods Inf. Med. 47 (2) (2008) 117-123.

[4] G. Ellingsen, K. Roed, The role of integration in health-based information infrastructures, J. Comput. Support. Cooperat. Work 19 (2010) 557-584.

[5] T. Greenhalgh, H.W.W. Potts, G. Wong, P. Bark, D. Swinglehurst, Tension and paradoxes in electronic patient record research: a systematic literature review using the meta-narrative method, Milbank Quart. 87 (4) (2009) 729-788.

[6] Integrated Digital Health in Denmark, National Strategy for Digitalization of Health Care 2008-2012, Integrated Digital Health in Denmark, Copenhagen, 2010.

[7] Ministry of Health, Action Plan for Electronic Patient Record, Ministry of Health, Copenhagen, 1996.

[8] A.K. Jha, D.M. DesRoches, E.G. Campbell, K. Donelan, S.R. Rao, T.G. Ferris, et al., Use of electronic health records in U.S. hospitals, N. Engl. J. Med. 360 (2009) 1628-1638.

[9] K.A. Jha, C.M. DesRoches, P.D. Kralovec, M.S. Joshi, A progress report on electronic health records in U.S. hospitals, Health Aff. (Millwood) 29 (10) (2010) 1951-1957.

[10] L.M. Bonner, C.E. Simons, L.E. Parker, E.M. Yano, J.E. Kirchner, To take care of patients": qualitative analysis of Veterans Health Administration personnel experiences with a clinical informatics system, Implement. Sci. 5 (63) (2010).

[11] C. Chen, T. Garrido, D. Chock, G. Okawa, L. Llang, The Kaiser Permanente Electronic Health Record: transforming and streamlining modalities of care, Health Aff. (Millwood) 28 (2) (2009) 323-333.

[12] L.M. Markus, C. Tanis, The enterprise system experience from adoption to success, in: R.W. Zmud (Ed.), Framing the Domains of IT Management: Projecting the Future through the Past, 2000, pp. 173-207.

[13] F. Nah, J. Lau, J. Kuang, Critical factors of successful implementation of enterprise systems, Business Process Manage. 7 (2001) 285-296.

[14] E. Ammenwerth, S. Gräber, G. Herrmann, T. Bürkle, J. König, Evaluation of health information systems - problems and challenges, Int. J. Med. Inf. 71 (2003) 125-135.

[15] L. Häkkinen, O. Hilmola, ERP evaluation during the shakedown phase: lessons from an after-sales division, Inf. Syst. J. 18 (2008) 73-100.

[16] W.H. DeLone, E.R. McLean, The DeLone and McLean model of information systems success: a ten-year update, JMIS 19 (4) (2003) 9-30.

[17] D.L. Goodhue, R.L. Thompson, Task-technology fit and individual performance, MIS Quart. 19 (1995) 213-236.

[18] A. Rai, S.S. Lang, R.B. Welker, Assessing the validity of the IS success models: and empirical test and theoretical analysis, Inf. Syst. Res. 13 (1) (2002) 50-69.

[19] P.B. Seddon, M. Kiew, A partial test and development of the DeLone and McLean model of IS success, Inf. Syst. Res. 8 (3) (1997) 240-253.

[20] P.B. Seddon, A respecification and extension of the DeLone and McLean model of IS success, Inf. Syst. Res. 8 (3) (1997) 240-253.

[21] N.H. Benbasat, D.K. Goldstein, M. Mead, The case research strategy in studies of information systems, MIS Quart. 11 (1987) 369-386.

[22] P. Nykänen, J. Brender, J. Talmon, N. de Keizer, M. Rigby, M. Beuscart-Zephir, et al., Guideline for good evaluation practice in health informatics (GEP-HI), Int. J. Med. Inf. 80 (December (12)) (2011) 815-827.

[23] R.K. Yin, Case Study Research. Design and Methods, Sage Publications, Newbury Park, CA, USA, 1991.

[24] P.J. Scott, J.S. Briggs, A pragmatist argument for mixed methodology in medical informatics, J. Mixed Methods Res. 3 (3) (2009) 223-241.

[25] B. Kaplan, D. Duchon, Combining qualitative and quantitative methods in information systems research: a case study, MIS Quart. 12 (4) (1988) 571-586.

[26] B. Kaplan, Evaluating informatics applications-some alternative approaches: theory, social interactionism, and call for methodological pluralism, Int. J. Med. Inf. 64 (November (1)) (2001) 39-56.

[27] J.I. Westbrook, J. Braithwaite, A. Georgiou, A. Ampt, N. Creswick, E. Coiera, et al., Multimethod evaluation of information and communication technologies in health in the context of wicked problems and sociotechnical theory, J. Am. Med. Inf. Assoc. 14 (November (6)) (2007) 746-755.

[28] J. Campion, L.R. Waitman, A.K. May, A. Ozdas, N.M. Lorenzi, C.S. Gadd, Social, organizational, and contextual characteristics of clinical decision support systems for intensive insulin therapy: a literature review and case study, Int. J. Med. Inf. 79 (January (1)) (2010) 31-43.

[29] B. Kaplan, Addressing organizational issues into the evaluation of medical systems, J. Am. Med. Inf. Assoc. 4 (3) (1997) 94-101.

[30] R.J. Lilford, J. Foster, Evaluating eHealth: how to make evaluation more methodologically robust, PLoS Med. 6 (11) (2009).

[31] J.S. Ash, D.F. Sittig, R. Dykstra, E. Campbell, K. Guappone, The unintended consequences of computerized provider order entry: findings from a mixed methods exploration, Int. J. Med. Inf. 78 (April (Suppl. 1)) (2009) S69-S76. 
[32] M.M. Yusof, J. Kuljis, A. Papazafeiropoulou, L.K. Stergioulas, An evaluation framework for Health Information Systems: human, organization and technology-fit factors (HOT-fit), Int. J. Med. Inf. 77 (June (6)) (2008) 386-398.

[33] P. Pluye, R.M. Grad, N. Mysore, L. Knaapen, J. Johnson-Lafleur, M. Dawes, Systematically assessing the situational relevance of electronic knowledge resources: a mixed methods study, J. Am. Med. Inf. Assoc. 14 (September (5)) (2007) 616-625.

[34] J. Green, C. McClintock, Triangulation in evaluation: design and analysis issues, Eval. Rev. J. Appl. Soc. Res. 9 (5) (1985) 523-545.

[35] J. Kirk, M. Miller, Reliability and Validity in Qualitative Research, Sage, London \& New Delhi, 1986.

[36] A. Likourezos, D. Chalfin, D.G. Murphy, B. Sommer, K. Darcy, S.J. Davidson, Physician and nurse satisfaction with an electronic medical record system, J. Emerg. Med. 27 (4) (2004) 419-424.

[37] T.M. Somers, K. Nelson, J. Karimi, Confirmatory factor analysis of the end-user computing satisfaction instrument: replication within an ERP domain, Decis. Sci. 34 (2003) 595-621.

[38] J.C. Benneyan, R.C. Lloyd, P.E. Plsek, Statistical process control as a tool for research and health care improvement, Qual. Saf. Health Care 12 (2003) 458-464

[39] C. Lovis, R.H. Baud, P. Planche, Power of expression in the electronic patient record: structured data or narrative text? Int. J. Med. Inf. 58-59 (2000) 101-110.

[40] S.B. Johnson, S. Bakken, D. Dine, S. Hyun, E. Mendonca, F. Morrison, et al., An electronic health record based on structured narrative, J. Am. Med. Inf. Assoc. 15 (1) (2008) 54-64.

[41] S. Vikkels $\varnothing$, Subtle redistribution of work, attention and risks: electronic patient records and organisational consequences, Scand. J. Inf. Syst. 17 (1) (2005) 3-30.

[42] T. Christensen, A. Grimsmo, Instant availability of patient records, but diminishing availability of patient information: a multi-method study of GP's use of electronic patient records, BMC Med. Inf. Decis. Making 8 (12) (2008).

[43] M.C. Mazzoleni, P. Baiardi, I. Giorgi, G. Franchi, R. Marcosi, M. Cortesi, Assessing user satisfaction through perception of usefulness and ease of use in the daily interaction with a hospital information system, in: Proc. AMIA Annu. Fall Symp., 1996, pp. 752-756.

[44] R.T. O'Connell, C. Cho, N. Shah, K. Brown, R.N. Shiffman, Take note(s): differential EHR satisfaction with two implementations under one roof, J. Am. Med. Inf. Assoc. 11 (2004) 43-49.

[45] N. Urbach, S. Smolnik, The state of research on information systems success, Business Inf. Syst. Eng. 1 (4) (2009) 315-325.

[46] S. Petter, W. DeLone, E. McLean, Measuring information systems success: models, dimensions, measures, and interrelationships, Eur. J. Inf. Syst. 17 (3) (2008) 236-263.

[47] S. Petter, A. Fruhling, Evaluating the success of an emergency response medical information system, Int. J. Med. Inf. 80 (7) (2011) 480-489.

[48] G.O. Otieno, T. Hinako, A. Motohiro, K. Daisuke, N. Keiko, Measuring effectiveness of electronic medical records systems: towards building a composite index for benchmarking hospitals, Int. J. Med. Inf. 77 (10) (2008) 657-669.

[49] K. Häyrinen, K. Saranto, P. Nykänen, Definition, structure, content, use and impacts of electronic health records: a review of the research literature, Int. J. Med. Inf. 77 (5) (2008) 291-304.

[50] M.J. van der Meijden, H.J. Tange, J. Troost, A. Hasman, Determinants of success of inpatient clinical information systems: a literature review, J. Am. Med. Inf. Assoc. 10 (3) (2003) 235-243.

[51] D.A. Ludwick, J. Doucette, Adopting electronic medical records in primary care: lessons learned from health information systems implementation experience in seven countries, Int. J. Med. Inf. 78 (2009) 22-31.

[52] C. Bossen, R. Markussen, Infrastructuring and ordering devices in health care: medication plans and devices at a hospital ward, J. Comput. Support. Cooperat. Work 19 (6) (2010) 615-637.

[53] C. Bossen, Accounting and co-constructing: the development of a standard for electronic health records, J. Comput. Support. Cooperat. Work 20 (6) (2011) 473-495.

[54] N. Urbach, B. Müller, The updated DeLone and McLean model of information systems success, in: Y.K. Dwivedi, M.R. Wade, S.L. Schneberger (Eds.), Information Systems Theory, 28th ed., Springer, New York, 2012, pp. 1-18. 